\title{
Residents' risk perceptions on Covid-19 and the impacts of social distancing in Nigeria.
}

\author{
Babatunde Femi Akinyode*
}

A R T I C LE IN F O

Received: July 25, 2020.

Received in revised form:

November 01, 2020.

Accepted: November 10, 2020.

Published online:

November 27, 2020
A B S T R A C T

COVID-19 or Coronavirus, a recent devastating and marauding infectious disease, is indeed a worldwide problem and has become a public health emergency of international concern. This study aimed to examine the residents' perception on COVID-19 and the impacts of social distancing in Nigeria. Quantitative technique was adopted in the study and the data was generated with the aid of computer based online questionnaire administration among 1567 respondents. Different analytical techniques such as mean and standard deviation scores, One-way ANOVA-test, average index and correlation analysis were performed. The study reveals positive relationship among factors that influence risk perception on COVID-19. Pearson Correlation analysis reveals strong relationship between residents' worry about COVID-19 and lockdown for the control of coronavirus disease. High residents' risk perception in Nigerian cities designates that COVID-19 is perceived as a health challenge and encourages most residents to maintain social distancing without considering numerous repercussions. Serious and urgent attention to alleviate these repercussions among the populace is of necessity.

Key words: Coronavirus - Covid-19-Perceptions - Risk - Social Distancing

To cite this article: Akinyode, B. F., (2020). Residents' risk perceptions on Covid-19 and the impacts of social distancing in Nigeria. Urbana, XXI. Retrieved from http://www.urbanauapp.org/ https://doi.org/10.47785/urbana.2.2020

\footnotetext{
* Department of Urban and Regional Planning, Faculty of Environmental Sciences, Ladoke Akintola University of Technology, Postcode 210214, P.M.B.4000, Ogbomoso, Oyo state, Nigeria. Corresponding e-mail Address: bfakinyode@lautech.edu.ng, Mobile Nos: +2348033955103,+2348053028722
} 


\section{Introduction}

COVID-19 (Coronavirus Disease-2019) is the disease caused by the virus SARS-COV-2 (Cortegiani, Ingoglia, Ippolito, Giarratano, \& Einav, 2020; Deslatte, 2020), a new type of coronavirus. Some other common members of the coronavirus family include cold and severe acute respiratory syndrome (SARS). This group of viruses often connected with the crossover of animal viruses to humans. The new virus has caused a Pandemic; it is extremely contagious and can lead to death (Cortegiani et al., 2020; Zhu et al., 2020). It has spread throughout the world and become public health emergency of international concern. The advent of COVID19 within every city in Nigeria poses health challenge to almost every residents in Nigerian cities that the disease can easily spread among them. Despite reports from several countries on the wide spread of the disease and many sequel studies from various perspectives, residents' risk perception on the pandemic is yet to be given any serious attention. (Singh et al., 2020).

At the beginning of the COVID-19 pandemic, Nigerian government was lethargic. This nonchalant attitude on the part of the government was exhibited by non-enforcement of lockdown policy within the nation, non-closure of her boarders and ports, especially international airports, and repatriation of returnees from overseas countries to Nigeria. This situation eventually led to a wide spread of the infectious disease among the citizens, and consequently, to a great health challenge. There is, therefore, fear of the different impacts this might have among the populace. Residents' health is recently being threaten and there is no effective drugs at the moment to treat COVID-19 being a new infectious disease (Zhu et al., 2020). As a result, the health workers are also exposed to risk because of inadequate health care facilities. Although many researchers in china and other countries have started carrying out clinical researches with the aim of diagnosing the cause of COVID-19, treating the victims and preventing the spread since its outbreak was firstly reported in Wuhan of China in December 2019, no concrete solution has been found until the moment. The contagious nature of the disease led to the imposition of social distancing policy in many countries, Nigeria not excluded.

Social distancing policy imposed by the government led to the close down of all educational institutions in the country from elementary to tertiary level. The serious challenge this has caused students is fluctuating educational landscape and indefinite prolongation of course duration. (Chick et al., 2020). The situation has created fear of losing job among the private educational workers and being infected of the disease among Nigerian populace. While Nigerian government keeps on searching for intervention measures in terms of vaccination and preventive measures to curtail the spread of the infectious disease, Nigerian residents' are expected to comply with recommended social distancing guidelines. These guidelines include restrictions on inter-states travelling, washing of hands regularly, avoidance of large gatherings of people; avoiding shaking of hands with people, using of facemask and applying of hand sanitizer. This embraces residents' ranking the advantages of social distancing over its prices (Xie, Campbell, \& Zhang, 2020). The implications of ongoing social distancing policy and compliance attitudes of the populace in order not to be infected of the disease become a matter of concern. However, these likely implications are yet to be ascertained in existing literature and more especially in Nigerian context. 
This paper focuses on the risk perception of residents and the impacts of social distancing in Nigeria. It was hypothesised that, there are differences in terms of residents' risk perception, their awareness about the incidence of COVID-19 Pandemic and the impacts of social distancing in Nigeria based on residents' socio-economics attributes. Six formulated research questions for this study as followed compliment the hypothesis:

a. What is the level of awareness and knowledge of the residents about COVID-19?

b. What are the sources of residents' awareness about COVID-19?

c. What are the measures being adopted by the residents to prevent being infected?

d. How worried are the residents about COVID-19?

e. What are the effects of social distancing on the life and activities of the residents?

f. Does lockdown for covid-19 have significant effects on the daily activities of the residents?

Testing of the hypothesis and achievement of the aim of the study will answer the research questions formulated. The rest of the paper is organised as follows: The next section explains the methods and materials for the study that gives brief description of the variables, sample size, sample techniques, data analysis, interpretation and presentation that are used. This is followed by the review of existing literature. The data, empirical results and findings are then presented and discussed before the conclusion and policy implications of the paper are summarised.

Methods and Materials: The study made use of extensive quantitative technique of data collection through a structured questionnaire to elicit information for the study. The questionnaire focused on residents' risk perceptions on COVID-19 and the impacts of social distancing in Nigeria. It was divided into two sections. Section A of the questionnaire focused on the socio-economic attributes of the respondents while Section B centred on residents' risk perceptions on COVID-19 and their attitudes towards social distancing in Nigeria. Section B consisted of six sub-sections namely level of awareness and knowledge of COVID-19, sources of awareness about COVID-19, measures to prevent being infected, residents' level of worry about COVID-19, effects of social distancing and effects of lockdown for COVID-19. The Section A was designed as multiple-choice questions while Section B was designed in a fivepoint Likert scale format to elicit information among the residents within cites in Nigeria. There was no provision for neutral option. This was to enable all the respondents take a stand for each question item. (Toyin Sawyerr \& Yusof, 2013). The sub-sections I and IV of the section B were designed in 5 points Likert scale format ranging from very low which was given 1 point to very high which was given 5 points on the rate of awareness of COVID-19 and level of worry of the respondents about COVID-19 respectively.

Likert Scales are psychometric response scales primarily used in questionnaires to obtain participant's preferences or degree of agreement with a statement or set of statements. Likert scales are non-comparative-scaling techniques and unidimensional (only measure a single trait) in nature. Respondents are asked to indicate their level of agreement with a given statement by way of an ordinal scale. The sub-sections II, III, V and VI of section B ranges from strongly disagree which was given 1 point to strongly agree which was given 5 points on the sources of awareness about COVID-19, measures to prevent being infected of COVID-19, effects of social distancing and effects of lockdown for COVID-19 respectively. Questionnaire 
was administered through computer based online survey among 1567 respondents. Computer based online survey was adopted in order to avoid close contact with the respondents and to maintain social/physical distancing. The computer based questionnaire administration was conducted between May 7, 2020 and May 30, 2020. SurveyMonkey is an online platform designed for social science and environmental research that has advantages over using physical and manual administration of questionnaire. It has the capability and effectiveness of collecting quick information from respondents without physical contact.

The questionnaire was distributed to people through WhatsApp, Facebook Messenger and email addresses of different respondents. The medium of sending the questionnaire to each respondents depends on the available medium to the prospective respondents. The questionnaire was available to respondents with online facilities and email addresses within Nigeria regardless of their socio-economic status. The email address of each respondent was required in the questionnaire in order to serve as control for the administration and to prevent duplication of answer by respondents. Any respondent without an email address was not able to submit after the completion of the questionnaire. All respondents who met the condition and was able to complete their questionnaire were used for the analysis of the study. However, no statistical technique was used to determine the sample sizes due to computer based online survey adopted.

The analysis of the available data started with harvesting of the completed questionnaires from the online by downloading the data and saving it in Excel format. This is followed by importing the data into the SPSS for further analysis. Although, the online generated automated descriptive analysis, this automated analysis was discarded in order to give room for data cleaning. The use of descriptive, correlation, ANOVA and Average Index were used for the analysis. Descriptive analysis was used to examine the frequency distribution of variables such as the socio-economic variables and correlation analysis deals with the relationship among different variables used to measure the risk perception and attitudes of residents towards social gathering. ANOVA, on the other hand was used to determine if there is any difference in factors that influence residents' perception based on their socio-economics attributes. This aimed to find any significant relationships between residents' socio-economics attributes and various factors that influence their perception. Average Index measures residents' risk perceptions on COVID-19 and the impacts of social distancing. This aimed at exploring the perception of residents on COVID-19 and the impacts of social distancing to control the spread of coronavirus disease among the residents.

Validity and Reliability of Data: Statistical validity and reliability tests were performed with the aid of SPSS Version 22 to confirm that the statistical data were significant. The validity centred on scores, instruments or research designs through Kaiser-Meyer-Olkin (KMO) measure of sampling adequacy and Bartlett's test of sphericity. Cronbach's Alpha accessed the internal consistent reliability of the survey instrument. The Reliability and Adequacy Tests for the entire variables were performed in the study. The result of the Cronbach's coefficient alpha of Reliability test indicated greater reliability and Kaiser-Meyer-Olkin (KMO) of validity test also showed that the instrument truly measured what it was supposed to measure. The aggregate Cronbach's alpha coefficient value of 0.911 as shown in Table I was considered sufficiently reliable and good internal consistency based on some scholars ((Hair, Black, Babin, \& 
Anderson, 2010; Khozaei, Ayub, Hassan, \& Khozaei, 2010; Newton \& Meyer, 2010; Toyin Sawyerr \& Yusof, 2013). The study also recorded higher respondents of 1567 administered questionnaires with $\mathrm{KMO}$ value of 0.845 implies reliable, adequate and valid survey sampling (Field, 2009).

Table I: Reliability and Validity Test

\begin{tabular}{|l|r|r|l|l|}
\hline Variables & $\begin{array}{r}\text { Number } \\
\text { of Items }\end{array}$ & $\begin{array}{l}\text { Cronbach's } \\
\text { Alpha } \\
\text { coefficient }\end{array}$ & $\begin{array}{l}\text { Aggregate } \\
\text { Cronbach's } \\
\text { Alpha } \\
\text { coefficient }\end{array}$ & $\begin{array}{l}\text { Kaiser- } \\
\text { Meyer-Olkin } \\
\text { (KMO) }\end{array}$ \\
\hline Awareness & 8 & 0.649 & & 0.721 \\
Sources of Awareness & 8 & 0.719 & & 0.684 \\
Preventive Measures & 23 & 0.889 & & 0.884 \\
Worry about COVID-19 & 9 & 0.913 & 0.911 & 0.896 \\
Effects of Social Distancing & 12 & 0.904 & & 0.898 \\
Effects of Lockdown for & 11 & 0.875 & & 0.886 \\
COVID-19 & & & & \\
\hline
\end{tabular}

Source: Field Survey, 2020.

In addition, validity and reliability tests for each of the sections of the questionnaire were also performed to confirm the significance of each of the statistical data in each of the sections. These were conducted on all the variables and met the specification of some scholars that specified that a Cronbach's alpha coefficient of an item between 0.52 and 0.7 should be considered sufficiently reliable and good internal consistency (Foubert, Tepper, \& Morrison, 1998; Hair et al., 2010; Khozaei et al., 2010; Pallant, 2007; Toyin Sawyerr \& Yusof, 2013). Application of maximum likelihood parameter estimation with listwise deletion of missing cases was made. The result of the reliability and adequacy test indicated greater reliability with Cronbach's alpha coefficient ranges from 0.684 to 0.898 while Kaiser-Meyer-Olkin (KMO) of validity test also showed that the instrument truly measured what it was supposed to measure as shown in Table I.

Density of Residence: The survey was conducted within the three density areas namely low, medium and high-density areas. Residents living within the medium density areas constituted the largest percentage of the respondents. They present $69.0 \%$ of the total respondents. This is followed by those living in the low density area with $18.5 \%$ of the total respondents while the respondents living in the high density area are the least among the respondents with $12.5 \%$ of the total respondents as shown in the Table II. Low response from high-density area may be attributed to the method of data collection, which is through online. Majority of the residents living in high-density areas cannot be reached, because they do not have access to WhatsApp, Facebook Messenger and email addresses through which the questionnaire was sent. The few 
respondents who were reached within high density areas are likely to be educated people and students who for social attachment reasons are living with their extended family members in the area.

Table II: Density of the Residence

\begin{tabular}{|l|r|r|r|r|}
\hline & Frequency & Percent & Valid Percent & Cumulative Percent \\
\hline Valid Low Density & 290 & 18.5 & 18.5 & 18.5 \\
Medium Density & 1082 & 69.0 & 69.0 & 87.6 \\
High Density & 195 & 12.5 & 12.5 & 100.0 \\
Total & 1567 & 100.0 & 100.0 & \\
\hline
\end{tabular}

Source: Field Survey, 2020.

Literature Review: The occurrence of COVID-19 suspected to be connected to the seafood market initially emanated from Wuhan city, Hubei province of China in December 2019 (Zhu et al., 2020). The symptoms of the disease are different respiratory infection symptoms like fever, dry cough, pneumonia and death. The Chinese constitute the largest infected people among over 80,000 people that have been infected around the world by Feb 30, 2020 and Hubei province in China was the utmost severe region where the infection outbreaks was obvious (Zhu et al., 2020). Several countries throughout the world including Nigeria and other African countries are also experiencing the spread of COVID-19. This consequently brings great challenges to residents' health in all the countries.

The warning in mid-March 2020 by state and local officials in the United States on Stay-at-Home (SAH) orders for residents to remain at home except to do essential tasks was to prevent two million Americans from risk of death through the COVID-19 Pandemic (ChaeWon, Peter, Todd, \& Preston, 2020). Besides, the Stay-at-Home order was also to reduce the spread and brutality of the coronavirus pandemic and many from confronting indefinite medical impediments among the residents. Friedson, Drew, Joseph, and Dhaval (2020) confirmed that the number of cases of COVID-19 reduced in California by 125.5 to 219.7 per 100,000 population and about 400 job lost per life saved by the implementation of stay at home policy within three weeks of implementation.

However, informal settlement, inadequate housing and homelessness are potential to increase spread of disease and severity of Pandemic (Henwood, Redline, \& Lahey, 2020; WHO, 2016). The neglect in emergency disease control strategies for COVID-19 affected populace despite that health care is human right (Singh et al., 2020). Permanent supportive housing (PSH) in Los Angeles were mainly for highly vulnerable homeless aged adults that require in-home supports in the study of Henwood et al. (2020). These people were exposed to risk of COVID-19 and needed protective measures. The study revealed that majority of these tenants considered COVID-19 to be a very serious and their health were threatened. They were conscious of the importance of taking preventive measures such as handwashing and social distancing. 
Chick et al. (2020) opined that the future consequence of COVID-19 pandemic on surgical education through provision of care and safety to both patients, trainees and staff would be enormous. The recommended social distancing and avoiding gatherings with more than ten people prevented in-person academic activities like teaching conferences, morbidity and mortality conferences and simulation laboratories. This policy of social distancing and avoidance of large gathering will affect and lower the standard of education and exposure of the students in every aspect of their education (Chick et al., 2020). This is a great challenge for educational sector. Chick et al. (2020) were of opinion that, urgent and necessary steps to safeguard the quality of educational sector during this pandemic period for better future education is of importance. However, the steps should not jeopardise the safety and health of both the students and their teachers at all levels of education. Gondauri and Batiashvili (2020) studied the connection amongst human mobility and the spread of viral infection aimed at exploring the correlation between mobility trends and the spread of Covid-19 virus. The study revealed that the strength of pedestrians, traffic and transit traffic within 15-20 days of the study affected the spread of the virus.

Xie et al. (2020) study revealed an innovative intellectual basis of social distancing compliance during the early stage of COVID-19 Pandemic in the U.S. Discrete differences in social distancing compliance partly ascribed to individual's socio-economic status to appraise the exact advantages of the endorsed guidelines for social distancing. Nevertheless, Coronavirus outbreak that led to stay at home policy has considerable affected economy and firm incomes in US which consequently caused setbacks to the labour market (Coibion, Yuriy, \& Michael, 2020; Hassan, Stephan, Laurence van, \& Ahmed, 2020; Lewis, Mertens, \& James, 2020). Coibion et al. (2020) survey on household revealed that the participation of labour market fell abruptly and 20 million people lost their jobs within the short period of Pandemic. ChaeWon et al. (2020) used actual unemployment insurance claims to determine how stay-athome orders affected employment using evidence from high frequency claims data and found out that, stay-at-home orders had significant effects on employment. However, stay-at-home orders accounted for a slight percentage of the total rise in unemployment, which implies that there would be limitation to economic recovery without stay-at-home orders. The majority of the upsurge in unemployment connected with coronavirus predicament was due to decreased consumer feeling, stock market interferences, and social distancing (ChaeWon et al., 2020). Stay-at-home orders are required to reduce the spread of COVID-19 but the orders are likely to increase the recession in national economy because the orders disrupted the labour markets. The economic dimension of the Pandemic became a point of emphasis throughout the nation as many citizens are soliciting for relax on social distancing. This implies that the higher the mortalities, the higher the economic losses and divergence from experts' direction as to relaxation of stay-at-home orders on business and movement (Deslatte, 2020). Deslatte (2020) examined whether the perceived expertise or authority influenced the social-distancing preferences of citizens and discovered that authority positively restrained the public health effects compared with if there is no authority. Besides, expert authority negatively restrained the effects. Nonetheless, the housing condition of informal settlement and homelessness that constituted sharing of bathroom and toilet facilities in addition with those tenants with mental health that have no access to hygienic food items, home and medication delivery cannot observe social distancing and consistent handwashing. Protective measures like social 
distancing and handwashing therefore became a challenge to those residing in such housing condition or along the streets.

In Nigeria and other African countries, COVID-19 is still a new infectious disease yet to be understood and no effective drugs for its treatment. As a result, confirmed cases and death are increasing on daily basis. This has become a severe threat to the people's health and concern to the government, health workers, policy makers, planners, other professionals and entire citizens of the nation. In order to stop the spread of this infectious disease among the residents, government has to resolve into preventive measures such as avoidance of inter and intra state travelling, regular washing of hands, avoidance of large gatherings of the people; avoidance of hand shaking, using of facemask and hand sanitizer. The effectiveness of these recommended preventive measures depends on residents' acquiescence with them. However, until now, there is no enough literature that has appraised the level of residents' compliance to these preventive measures, the impacts of social distancing or that have evaluated the residents' risk perception on the infectious disease especially in Nigeria. Therefore, this study try to bridge this gap and add to the existing literature by evaluating the residents' risk perceptions on covid-19 and the impacts of social distancing placed by the Nigerian government. This aims to provide workable suggestion towards environment that is healthy for the residents to live during and after the COVID-19 Pandemic.

\section{Analysis of Results and Discussion}

Respondents' profile: To define the risk perception of residents on COVID-19 and the impacts of social distancing, the importance and understanding of respondents' socio-economic status cannot be over emphasised. The socio-economic attributes considered in the survey included sex, age, marital status, religious affiliation, educational level attainment, employment status, household size and estimated monthly income. $75.0 \%$ of the respondents are male and $25.0 \%$ are females. $12.1 \%$ of the respondents are less than 21 years of age while $39.6 \%$ fall within the age group $21-30$ years. $18.8 \%$ of the respondents are within the age bracket of $31-40$ years while those within the age bracket of 41 - 50 years constitutes $18.8 \%$ of the total respondents and the remaining $14.4 \%$ are above 50 years. Majority of the respondents are middle aged within the age bracket 50 years with $85.6 \%$ of the total respondents. This implies that, middleaged people are the majority of the people that are accessible to social media and online facilities in Nigeria.

Majority of the respondents are single. Single respondents constitute $53.0 \%$ of the total respondents while Married but Single is the least among the respondents. Married but Single constitutes just $1.9 \%$ of the total respondents. $45.1 \%$ of the total respondents are married. The single that constitutes the majority of the respondents reflects on the largest percentage of the respondents that are HND/BSc holders and Students. There are two major religion affiliations of the respondents in this study and these include Christianity and Islam. Christianity constitutes the major religion affiliations of the respondents with $78.0 \%$ of the total respondents while the remaining respondents of $22.0 \%$ belongs to Islam religion. The survey also undertook a study on educational level attainment of the respondents. The survey reveals that respondents with HND/BSc certificate constitutes the largest percentage of the respondents with $56.6 \%$ of the total respondents. $\mathrm{MSc} / \mathrm{PhD}$ holders follow this with $31.3 \%$ of the total respondents. This implies that $87.9 \%$ of total respondents are educated with minimum of HND/BSc certificates. 
As a result, the researcher adjudged the categories of the respondents to be qualified to give a rightful risk perception on COVID-19 and impacts of social distancing. Besides, other respondents include those with $\mathrm{NCE} / \mathrm{OND}$ and Elementary Education certificates that constitutes $5.4 \%$ and $5.7 \%$ respectively. The remaining $1.0 \%$ are those with no formal education. Despite the fact that majority of the respondents obtained HND/BSc certificate, $40.8 \%$ of the respondents are students. There are different categories of the students and these include undergraduate and postgraduate students. Postgraduate students are those undergoing MSc and PhD studies. Undergraduate students include those that have already obtained HND certificate but presently undertaking BSc program. The study failed to identify these different categories of students.

Government Employee takes the next largest percentage of the respondents with $22.7 \%$ of the total respondents followed by self-employed with $14.2 \%$ of the total respondents. Clergy and unemployed respondents take $11.8 \%$ and $10.5 \%$ respectively. This implies that, respondents with different educational background and employment status will have different attitudes towards social distancing with different effects among them. Household size between three and five members constitutes the highest house size. This amount to $57.2 \%$ while $15.3 \%$ and $27.4 \%$ are the respondents with house size between one and two members and six members respectively. The largest percentage of the educated respondents reflects on the house size. The educated people do not believe in large number of family members. This implies that majority of the respondents do not have more than three children within their household (that is a father, a mother and three children). Estimated monthly income of the respondents was another socioeconomic attribute that this survey embarked upon. The educational background and employment status of the respondents reflects in their estimated monthly income. Majority of the respondents earns above $\mathrm{N} 120,000.00$ per month (1 USD $=\$ 3387.06$ as in September 25, 2020). This constitutes $29.4 \%$ of the total respondents. This is followed by those that earn Less than $\$ 30,000.00$ with $34.1 \%$ of total respondents. This is resulted from the fact $40.8 \%$ of the total respondents are students. Majority of these students do not engage in paid jobs. Besides, $10.5 \%$ of the total respondents are unemployed. $16.3 \%, 15.1 \%$ and $5.1 \%$ earn between $\mathrm{N} 31,000.00$ and $\mathrm{N} 50,000.00$; $\mathrm{N} 51,000.00$ and $\mathrm{N} 90,000.00$ and between $\mathrm{N} 91,000.00$ $\mathrm{N} 120,000.00$ respectively.

Residents' risk perceptions on COVID-19: In order to determine the residents' risk perception on COVID-19, variables used to assess different factors were computed to transform into a single factor. This is to determine the overall residents' perceptions on COVID-19. The mean and standard deviation scores analysis were carried out as shown in Table III.

According to the result, the mean and standard deviation scores certifies that the deviation from mean score is high. Most of the residents' perception on various factors on COVID-19 is above average rating of 2.5 . The 2 can be rated as poor; 3 can be rated as slightly good while 4 can be rated as very good and 5 to be rated as excellent. This means, the residents' perception on the factors are within the rate of slightly good and very good indicates that the rating is good. 
Table III: Mean and Standard deviation scores of Respondents

\begin{tabular}{|l|r|r|r|r|r|r|}
\hline & Knowledge & $\begin{array}{c}\text { Awareness } \\
\text { Sources }\end{array}$ & $\begin{array}{c}\text { Preventive } \\
\text { Measures }\end{array}$ & $\begin{array}{c}\text { COVID-19 } \\
\text { Worriness }\end{array}$ & $\begin{array}{c}\text { Social } \\
\text { Distancing }\end{array}$ & $\begin{array}{c}\text { Lockdown } \\
\text { Effects }\end{array}$ \\
\hline V Valid & 1567 & 1567 & 1567 & 1567 & 1567 & 1567 \\
Missing & 0 & 0 & 0 & 0 & 0 & 0 \\
Mean & 3.7261 & 3.0453 & 3.9537 & 3.5541 & 3.9308 & 3.0453 \\
Standard & .54823 & .75662 & .60997 & 1.06781 & .84463 & .93674 \\
Deviation & & & & & & \\
\hline
\end{tabular}

Source: Field Survey, 2020.

Level of Residents' Awareness about COVID-19 Pandemic: The study hypothesised that, there is difference in terms of residents' risk perception, their level of awareness about COVID19 pandemic and impacts of social distancing in Nigeria based on residents' socio-economics attributes. This aimed to find any significance relationships between residents' socioeconomics attributes and their level of awareness about COVID-19 pandemic. To achieve this, application of One-way ANOVA-test was performed to review the socio-economics variables. The results submitted that, no difference exist $(\mathrm{P}<0.05)$ in terms of residents' awareness level about COVID-19 pandemic based on all their socio-economics attributes as shown in Table IV. This implies that, regardless of any socio-economics attributes of the respondents, their level of awareness about COVID-19 pandemic remains identical.

Social Distancing: The study move further to hypothesise if there is any difference in terms of residents' perception on effects of social distancing based on residents' socio-economics attributes. This aimed to find any significant relationships between residents' socio-economics attributes and their perception on effects of social distancing. The performance of One-way ANOVA-test application was made to review the socio-economics variables. The results submitted that, no difference exist $(\mathrm{P}<0.05)$ in terms of effects of social distancing based on all their socio-economics attributes as shown in Table $\mathrm{V}$. This suggests that, regardless of any socio-economics attributes of the respondents, the effects of social distancing remains the same. 
Table IV: One-way ANOVA-test: Awareness about the incidence of COVID-19 Pandemic

\begin{tabular}{|c|c|c|c|c|c|}
\hline \multicolumn{2}{|l|}{ Variables } & Sum of Squares & df & $\mathrm{F}$ & Sig. \\
\hline \multirow{3}{*}{ Gender } & Between Groups & 30.709 & 25 & 7.191 & .000 \\
\hline & Within Groups & 263.228 & 1541 & & \\
\hline & Total & 293.937 & 1566 & & \\
\hline \multirow{3}{*}{ Age } & Between Groups & 292.262 & 25 & 8.332 & .000 \\
\hline & Within Groups & 2162.218 & 1541 & & \\
\hline & Total & 2454.480 & 1566 & & \\
\hline \multirow{3}{*}{ Marital Status } & Between Groups & 530.364 & 25 & 5.839 & .000 \\
\hline & Within Groups & 5599.023 & 1541 & & \\
\hline & Total & 6129.387 & 1566 & & \\
\hline \multirow{3}{*}{ Religion Affiliation } & Between Groups & 26.732 & 25 & 6.800 & .000 \\
\hline & Within Groups & 242.311 & 1541 & & \\
\hline & Total & 269.043 & 1566 & & \\
\hline \multirow{2}{*}{$\begin{array}{l}\text { Educational Level } \\
\text { Attained }\end{array}$} & Between Groups & 115.756 & 25 & 7.643 & .000 \\
\hline & Within Groups & 933.567 & 1541 & & \\
\hline \multirow{5}{*}{ Employment Status } & Total & 1049.324 & 1566 & & \\
\hline & Between Groups & 433.475 & 25 & 7.215 & .000 \\
\hline & Within Groups & 3703.481 & 1541 & & \\
\hline & Total & 4136.956 & 1566 & & \\
\hline & Between Groups & 60.140 & 25 & 6.317 & .000 \\
\hline \multirow[t]{2}{*}{ Household Size } & Within Groups & 586.822 & 1541 & & \\
\hline & Total & 646.962 & 1566 & & \\
\hline \multirow{3}{*}{$\begin{array}{l}\text { Estimated Monthly } \\
\text { Income }\end{array}$} & Between Groups & 541.487 & 25 & 9.006 & .000 \\
\hline & Within Groups & 3706.107 & 1541 & & \\
\hline & Total & 4247.594 & 1566 & & \\
\hline
\end{tabular}

Source: Field Survey, 2020. Significant at 0.05 level (two tailed).

Residents' perception on their level of Awareness about COVID-19: In measuring residents' risk perceptions on COVID-19 and the impacts of social distancing in Nigeria precisely, residents were asked for their perception on their level of awareness about COVID-19, sources of the awareness, preventive measures, their worry about COVID-19, effects of social distancing and effects of lockdown for COVID-19. This aimed at exploring impact level of COVID-19 as per the residents' perception through the given variables. The result reveals that the average index for each of the attributes used to evaluate the awareness level of COVID-19 is almost the same. This implies that on the overall, residents' perception on the awareness level of COVID-19 is high if not very high. 
Table V: One-way ANOVA-test: Effects of Social Distancing

\begin{tabular}{|c|c|c|c|c|c|}
\hline & & Sum of Squares & $\mathrm{df}$ & $\mathrm{F}$ & Sig. \\
\hline & Between Groups & 37.271 & 42 & 5.269 & .000 \\
\hline Gender & Within Groups & 256.666 & 1524 & & \\
\hline & Total & 293.937 & 1566 & & \\
\hline & Between Groups & 441.613 & 42 & 7.961 & .000 \\
\hline Age & Within Groups & 2012.867 & 1524 & & \\
\hline & Total & 2454.480 & 1566 & & \\
\hline & Between Groups & 1129.809 & 42 & 8.200 & .000 \\
\hline Marital Status & Within Groups & 4999.578 & 1524 & & \\
\hline & Total & 6129.387 & 1566 & & \\
\hline & Between Groups & 34.857 & 42 & 5.401 & .000 \\
\hline Religion Affiliation & Within Groups & 234.186 & 1524 & & \\
\hline & Total & 269.043 & 1566 & & \\
\hline Educational Level & Between Groups & 171.470 & 42 & 7.088 & .000 \\
\hline Attained & Within Groups & 877.853 & 1524 & & \\
\hline & Total & 1049.324 & 1566 & & \\
\hline & Between Groups & 718.004 & 42 & 7.620 & .000 \\
\hline Employment Status & Within Groups & 3418.952 & 1524 & & \\
\hline & Total & 4136.956 & 1566 & & \\
\hline & Between Groups & 73.576 & 42 & 4.656 & .000 \\
\hline Household Size & Within Groups & 573.387 & 1524 & & \\
\hline & Total & 646.962 & 1566 & & \\
\hline Estimated Monthly & Between Groups & 710.062 & 42 & 7.283 & .000 \\
\hline Income & Within Groups & 3537.532 & 1524 & & \\
\hline & Total & 4247.594 & 1566 & & \\
\hline
\end{tabular}

Source: Field Survey, 2020. Significant at 0.05 level (two tailed).

For evaluating the impact variable of 'Awareness level of COVID-19', residents were given the options to indicate through 5-point Likert scale as shown in Table VI. Although, the practice of social distancing by the residents is low with average index of 2.63 and risk to be infected by the residents is also evaluated to be low with average index of 2.00 according to the result. The result of other attributes reveals that majority of the residents perceive the COVID-19 to be real, severe and contagious as well as health challenging through which infected people can die. This confirms the assertions of some scholars (Cortegiani et al., 2020; Zhu et al., 2020). 
Table VI: Rate of Awareness about COVID-19

\begin{tabular}{|l|l|l|l|l|l|l|r|r|}
\hline Items & 1 & 2 & 3 & 4 & 5 & Sample & \multicolumn{1}{l|}{$\begin{array}{l}\text { Total } \\
\text { Index }\end{array}$} & $\begin{array}{l}\text { Average } \\
\text { Index }\end{array}$ \\
\hline Incidence & 30 & 75 & 160 & 380 & 922 & 1567 & 6790 & 4.33 \\
Preventive Measure & 15 & 55 & 210 & 405 & 882 & 1567 & 6785 & 4.33 \\
Reality & 35 & 45 & 180 & 285 & 1022 & 1567 & 6915 & 4.41 \\
Contagious level & 50 & 90 & 310 & 430 & 687 & 1567 & 6315 & 4.03 \\
Risk to be infected & 652 & 500 & 250 & 90 & 75 & 1567 & 3137 & 2.00 \\
Virus caused disease & 35 & 80 & 280 & 525 & 647 & 1567 & 6370 & 4.07 \\
Infected people can die of & & & & & & & & 4.01 \\
the disease & 30 & 125 & 300 & 455 & 657 & 1567 & 6285 & \\
Social distancing practice & & & & & & & & \\
in area of residence & 345 & 415 & 420 & 257 & 130 & 1567 & 4113 & 2.63 \\
\hline
\end{tabular}

Note: $(1$ = Very Low; 2 = Low; 3 = Fairly High; 4 = High; 5 = Very High $)$

The high level of residents' awareness on the incidence, preventive measures, reality of the virus, transmission and that infected person can die helped them to be cautioned and took other necessary preventive measures in order not be infected of the virus. These preventive measures include avoidance of handwashing and use of hand sanitizer. As a result, majority of the residents are not at risk of being infected of the virus. Very few residents especially among the illiterates and self-employed residents that are not observing and practicing these preventive measures are likely to be those that are residing in high density areas. The likelihood reasons for this include level of their awareness and their socio-economic status. Besides, there is inadequate facilities such as water, waste disposal system and toilet facilities within the high density areas.

Residents' perception on effects of social distancing: Although, various variables that assess the effects of social distancing was already computed to transform into a single variable as the overall residents' perceptions on 'effects of social distancing'. The mean and standard deviation scores (3.93 and 0.84463 respectively) analyses carried out as shown in Table III indicates that the result certifies that, the deviation from mean score is high. This determines the overall residents' risk perception on effects of social distancing during COVID-19. However, effects of social distancing on different issues were investigated in this study. This aims at determining the level of residents' perception as per the effects of social distancing during COVID-19 Pandemic. Residents were to select from options to indicate the level of their agreement on the effects of social distancing through 5-point Likert scale between strongly disagree represented by 1 point and strongly agree represented by 5 points as shown in Table VII. The result of the analysis reveals that economic life, religious life and movement 
of people as well as the education of the students, relationship among colleagues and planned events are mostly affected by the social distancing with higher average index scores.

The effects of social distancing on the economic life of the people confirms the result of ChaeWon et al. (2020) who was of the opinion that increase in unemployment related with coronavirus dilemma was resulted from social distancing policy. The educational effect is in line with Chick et al. (2020) that saw social distancing as a challenge to education because of unstable educational setting and undefined changes of course time situation that affect and lower the standard of education and exposure of the students. Other effects of the social distancing resulted from COVID-19 include social life, marital life and relationship among neighbourhood residents with average index score of above 3.00. Social distancing also leads to depression and loneliness among the residents. Social distancing has the greatest impact on planned events as it ranked first position. In view of the imposed social distancing, many of the planned events were cancelled in Nigerian cities. The education of the students ranked second because of the closure of all the institutions at all levels. Movement of people ranked third as the impacts of social distancing. This consequently leads to depression and loneliness among the residents because of residents' inability to move out and travel anyhow as they desire. This implies that, there is limitation to the human right within the period of social distancing resulted from COVID-19.

Table VII: Residents' perception on Effects of Social Distancing

\begin{tabular}{|l|l|l|l|l|l|l|l|l|l|}
\hline Items & 1 & 2 & 3 & 4 & 5 & Sample & $\begin{array}{l}\text { Total } \\
\text { Index }\end{array}$ & $\begin{array}{l}\text { Average } \\
\text { Index }\end{array}$ & Rank \\
\hline Social life of the people & 140 & 75 & 225 & 375 & 752 & 1567 & 6225 & 3.97 & 7 th \\
Economic life of the people & 105 & 70 & 215 & 350 & 827 & 1567 & 6425 & 4.10 & 5 th \\
Religious life of the people & 80 & 85 & 185 & 327 & 890 & 1567 & 6563 & 4.19 & 4 th \\
Marital life of the people & 330 & 230 & 320 & 245 & 442 & 1567 & 4940 & 3.15 & 12 th \\
Education of the students & 65 & 60 & 120 & 282 & 1040 & 1567 & 6873 & 4.39 & 2nd \\
Movement of people & 75 & 70 & 210 & 270 & 942 & 1567 & 6635 & 4.23 & 3rd \\
Relationship among & 90 & 85 & 330 & 365 & 697 & 1567 & 6195 & 3.95 & 8th \\
neighbourhood residents & & & & & & & & & \\
Relationship among staff in & 60 & 115 & 235 & 380 & 777 & 1567 & 6400 & 4.08 & 6th \\
the place work/school & & & & & & & & & \\
Limits human right & 205 & 210 & 317 & 295 & 540 & 1567 & 5456 & 3.48 & 10 th \\
Cancellation of planned & 35 & 45 & 115 & 235 & 1137 & 1567 & 7095 & 4.53 & 1 st \\
events & & & & & & & & & \\
Leads to depression & 195 & 197 & 425 & 305 & 445 & 1567 & 5309 & 3.39 & 11th \\
Leads to loneliness & 120 & 167 & 375 & 305 & 600 & 1567 & 5799 & 3.70 & 9th \\
\hline
\end{tabular}

Note: $(1=$ Strongly Disagree; 2 = Disagree; 3 = Fairly Agree; 4 = Agree; $5=$ Strongly Agree $)$ 
Evaluation of Relationship among the factors: Efforts are also made to evaluate whether there is existence of positive relationship amongst the factors. To achieve this, Pearson correlation test was applied as shown in Table VIII. Although, the result reveals weak relationship amongst the factors, there is positive relationship amongst the factors indicating that the factors influence each other with different coefficient values. There is strong relationship between worry about COVID-19 and lockdown with .505 coefficient. It can be inferred from the result that, residents adhered to the policy of lockdown because of their worry about COVID-19. The lockdown policy aimed at achieving social distancing among the residents.

Table VIII: Correlations amongst the Factors

\begin{tabular}{|c|c|c|c|c|c|c|c|}
\hline \multicolumn{8}{|c|}{ Correlations ${ }^{b}$} \\
\hline & & $\begin{array}{c}\text { Level of } \\
\text { Awareness }\end{array}$ & $\begin{array}{c}\text { Sources of } \\
\text { Awareness }\end{array}$ & $\begin{array}{l}\text { Preventive } \\
\text { Measures } \\
\end{array}$ & $\begin{array}{l}\text { Worry about } \\
\text { COVID-19 }\end{array}$ & $\begin{array}{c}\text { Social } \\
\text { Distancing }\end{array}$ & $\begin{array}{l}\text { Effects of } \\
\text { Lockdown }\end{array}$ \\
\hline \multirow[t]{2}{*}{$\begin{array}{l}\text { Level of } \\
\text { Awareness }\end{array}$} & $\begin{array}{l}\text { Pearson } \\
\text { Correlation }\end{array}$ & 1 & $.313^{* *}$ & $.379^{* *}$ & $.336^{* *}$ & $.127^{* *}$ & $.210^{* *}$ \\
\hline & $\begin{array}{l}\text { Sig. (2- } \\
\text { tailed) }\end{array}$ & & .000 & .000 & .000 & .000 & .000 \\
\hline \multirow[t]{2}{*}{$\begin{array}{l}\text { Sources of } \\
\text { Awareness }\end{array}$} & $\begin{array}{l}\text { Pearson } \\
\text { Correlation }\end{array}$ & $.313^{* *}$ & 1 & $.343^{* *}$ & $.104^{* *}$ & $.088^{* *}$ & $.185^{* *}$ \\
\hline & $\begin{array}{l}\text { Sig. (2- } \\
\text { tailed) }\end{array}$ & .000 & & .000 & .000 & .000 & .000 \\
\hline \multirow[t]{2}{*}{$\begin{array}{l}\text { Preventive } \\
\text { Measures }\end{array}$} & $\begin{array}{l}\text { Pearson } \\
\text { Correlation }\end{array}$ & $.379^{* *}$ & $.343^{* *}$ & 1 & $.309^{* *}$ & $.153^{* *}$ & $.295^{* *}$ \\
\hline & $\begin{array}{l}\text { Sig. (2- } \\
\text { tailed) }\end{array}$ & .000 & .000 & & .000 & .000 & .000 \\
\hline \multirow[t]{2}{*}{$\begin{array}{l}\text { Worry about } \\
\text { COVID-19 }\end{array}$} & $\begin{array}{l}\text { Pearson } \\
\text { Correlation }\end{array}$ & $.336^{* *}$ & $.104^{* *}$ & $.309^{* *}$ & 1 & $.134^{* *}$ & $.505^{* *}$ \\
\hline & $\begin{array}{l}\text { Sig. }(2- \\
\text { tailed) }\end{array}$ & .000 & .000 & .000 & & .000 & .000 \\
\hline \multirow[t]{2}{*}{$\begin{array}{l}\text { Social } \\
\text { Distancing }\end{array}$} & $\begin{array}{l}\text { Pearson } \\
\text { Correlation }\end{array}$ & $.127^{* *}$ & $.088^{* *}$ & $.153^{* *}$ & $.134^{* *}$ & 1 & $.389^{* *}$ \\
\hline & $\begin{array}{l}\text { Sig. (2- } \\
\text { tailed) }\end{array}$ & .000 & .000 & .000 & .000 & & .000 \\
\hline \multirow[t]{2}{*}{$\begin{array}{l}\text { Effects of } \\
\text { Lockdown }\end{array}$} & $\begin{array}{l}\text { Pearson } \\
\text { Correlation }\end{array}$ & $.210^{* *}$ & $.185^{* *}$ & $.295^{* *}$ & $.505^{* *}$ & $.389^{* *}$ & 1 \\
\hline & $\begin{array}{l}\text { Sig. }(2- \\
\text { tailed) }\end{array}$ & .000 & .000 & .000 & .000 & .000 & \\
\hline
\end{tabular}

Source: Field Survey, 2020. **. Correlation is significant at the 0.01 level (2-tailed).

Recommendations and Conclusion: The threat of the COVID-19 Pandemic on the health of the residents with inadequate health care facilities resulted from emerging infectious diseases requires urgent attention. Proper control of this Pandemic requires collective efforts, supports and assistance of foreign countries, federal governments and philanthropists to ensure effective health care and management of COVID-19 nationwide. The residents without appropriate measures with inadequate health care facilities are expose to the risk of infection with COVID19. This can increase the spread of the disease with inability to control it. High density areas 
identified as informal settlements is likely to exhibit spread of COVID-19 easily due to their socio-economic status to observe preventive measures and inadequate infrastructural facilities like water, waste disposal system and toilet facilities. Observing of preventive measures such as washing of hands regularly, maintaining social distancing, attentive to cleanliness and practice proper hygiene and avoidance of buying materials in open markets as well as using of face mask and hand sanitizer is really a challenge to high density residents. This is resulted from socio-economic status of the majority of these residents. As hand washing is the major preventive measure for preventing the spread of the COVID-19. This preventive measure largely depends on the availability of adequate water supply and soap. Non-accessibility of adequate water supply and soap to wash hands regularly is a major problem in high density area. As a result, there is possibility of increase in mortality rate through COVID-19 if the disease spreads to the high density areas. Thoughtful and proactive measures are therefore highly necessary to prevent the spread of this disease to high density areas.

Overcrowding and congestion are accountable to increase the transmission of disease as witnessed in the spread of Ebola virus in Liberia in 2014 (Singh et al., 2020). The same experienced may be witnessed in the spread of COVID-19 within high density area where overcrowding and congestion are the matter. Government's mediations is of importance to prevent the spread of COVID-19 through upgrading of the environment to minimise overcrowding and congestion. This is because; social distancing and lockdown policies is enormous challenge to the populace within such community. Government should therefore be encouraged to see the issue blighted areas upgrading as a matter of necessity to improve the living standard of residents. Housing policy should give priority and make provision for high density residents in the housing programs with sufficient provision of portable water, road network, electricity, public toilet and other infrastructural facilities for better living. This is vital in reducing the spread of the COVID-19 among high density residents and prevent further spreading of the disease within the nation. This will also serve as proactive measures for such future occurrence. Education of the residents especially the illiterates and self-employed in high density areas on observing social distancing and complying with other preventive measures is highly importance. Provision for effective training among these residents on the importance of responding to appropriate measures will curtail the spread of the disease. These exigence strategies are to be made ready to compact the situation if the disease finally get to the high density areas.

This study has identified various variables that affect the residents' perception on COVID-19. It contributes to the body of knowledge in understanding the impacts of social distancing; the challenge of observing the preventive measures, social distancing and lockdown policies among high density residents that can consequently increase the mortality rate if the disease spreads to the high density areas. This study has also suggested strategies of controlling the spread of coronavirus disease especially among the high density residents. This knowledge will provide a framework for urban planners, researchers and policy makers to develop practicable strategies to alleviate the challenges, the spread and control of such disease as well as during future occurrence of such Pandemic.

However, the study needs replication to address some limitations and shortcomings of this study that warrant further exploration. For example, this study failed to address attitudes of residents on states levels and failed to compare the situation in Nigeria with countries outside 
Nigeria. Further study can therefore be conducted on the comparative analysis of residents' risk perception between different states within the nation. The research design does not limit the respondents to a particular locality for the questionnaire administration. The risk perception of the residents is examined on a general form but not specific to a particular setting. Besides, the use of computer based online survey through SurveyMonkey limited the respondents to those with online facilities and email addresses. Although, the questionnaires administered cut across every socio-economic status but those without online facilities and email addresses are not involved in the survey. The perception of the majority of less privileged and low-income residents cannot be represented in this study. The survey was conducted when the social distancing orders were still ongoing when fear of the Pandemic and not to be infected grip majority of the residents. It is necessary to conduct a survey after the social distancing orders might have been relaxed. This will serve as post-pandemic experience and will include those without online facilities and email address.

\section{References}

ChaeWon, B., Peter, B. M., Todd, M., \& Preston, M. (2020). Unemployment Effects of Stayat-Home Orders: Evidence from High Frequency Claims Data. Retrieved from IRLE Working Paper No. 101-120.: http://irle.berkeley.edu/files/2020/04/UnemploymentEffects-of-Stay-at-Home-Orders.pdf

Chick, R. C., Clifton, G. T., Peace, K. M., Propper, B. W., Hale, D. F., Alseidi, A. A., \& Vreeland, T. J. (2020). Using Technology to Maintain the Education of Residents During the COVID-19 Pandemic. Journal of Surgical Education, Article in Press, 1-4. doi:10.1016/j.jsurg.2020.03.018

Coibion, O., Yuriy, G., \& Michael, W. (2020). Labor Markets during the COVID-19 Crisis: A Preliminary View. (No. w227017). National Bureau of Economic Research.

Cortegiani, A., Ingoglia, G., Ippolito, M., Giarratano, A., \& Einav, S. (2020). A systematic review on the efficacy and safety of chloroquine for the treatment of COVID-19. Journal of Critical Care, In Press, 1-5. doi:10.1016/j.jcrc.2020.03.005

Deslatte, A. (2020). To shop or shelter? Issue framing effects and social-distancing preferences in the COVID-19 pandemic. Journal of Behavioral Public Administration, 3(1). doi:10.30636/jbpa.31.158

Field, A. (2009). Discovering Statistics Using SPSS (Third ed.). London: SAGE Publications Ltd.

Foubert, J. D., Tepper, R., \& Morrison, D. (1998). Predictors of student satisfaction in university residence halls. The Journal of College and University Student Housing, 27(1), 41-46.

Friedson, A. I., Drew, M., Joseph, J. S., \& Dhaval, D. (2020, April 2020). Did California's Shelter-in-Place OrderWork? Early Coronavirus-Related Public Health Benefits. [IZA Discussion Papers, No. 13160]. (Working Paper 26992). National Bureau of Economic Research. 
Gondauri, D., \& Batiashvili, M. (2020). The Study of the Effects of Mobility Trends on the Statistical Models of the COVID-19 Virus Spreading. Electronic Journal of General Medicine, 17(6:em243), 1-4. doi:10.29333/ejgm/8212

Hair, J. F., Black, W. C., Babin, B. J., \& Anderson, R. E. (2010). Multivariate Data Analysis: Overview of Multivariate Methods (Seventh Edition ed.). Pearson Prentice Hall: Upper Saddle River, New Jersey: Pearson Education International.

Hassan, T. A., Stephan, H., Laurence van, L., \& Ahmed, T. (2020). Firmlevel Exposure to Epidemic Diseases: Covid-19, SARS, and H1N1. (No. w26971). National Bureau of Economic Research.

Henwood, B. F., Redline, B., \& Lahey, J. (2020). Surveying Tenants of Permanent Supportive Housing in Skid Row about COVID-19. Retrieved from https://doi.org/10.1101/2020.04.17.20070052/ Accessed 12 May 2020.

Khozaei, F., Ayub, N., Hassan, A. S., \& Khozaei, Z. (2010). The Factors Predicting Students' Satisfaction with University Hostels, Case Study, Universiti Sains Malaysia. Asian Culture and History, 2(2), 148-158.

Lewis, D., Mertens, K., \& James, H. S. (2020). US Economic Activity during the Early Weeks of the SARS-Cov-2 Outbreak. (No. w26954). National Bureau of Economic Research.

Newton, P., \& Meyer, D. (2010). The Determinants of Urban Resource Consumption. Environment and Behavior, 44(1), 107-135. doi:10.1177/0013916510390494

Pallant, J. (2007). SPSS Survival Manual-A Step by Step Guide to Data Analysis Using SPSS for Windows (3rd Edition ed.). England: Open University Press.

Singh, L., Singh, N. S., Maldonado, B. N., Tweed, S., Blanchet, K., \& Graham, W. J. (2020). What does 'leave no one behind' mean for humanitarian crises-affected populations in the COVID-19 pandemic? BMJ Global Health, 1-3. doi:10.1136/bmjgh-2020-002540

Toyin Sawyerr, P., \& Yusof, N. A. (2013). Student satisfaction with hostel facilities in Nigerian polytechnics. Journal of Facilities Management, 11(4), 306-322. doi:10.1108/jfm-082012-0041

WHO. (2016). World Health Organization: What are the health risks related to overcrowding. Retrieved from Who. Available: https://www. who. int/ water_sanitation_ health/ emergencies/ qa/emergencies_qa9/ en/ Accessed 12 May 2020.

Xie, W., Campbell, S., \& Zhang, W. (2020). Working Memory Capacity Predicts Individual Differences in Social Distancing Compliance during the COVID-19 Pandemic in the U.S. On-line Working Paper Series.

Zhu, R.-f., Gao, Y.-1., Robert, S.-H., Gao, J.-p., Yang, S.-g., \& Zhu, C.-t. (2020). Systematic Review of the Registered Clinical Trials of Coronavirus Diseases 2019 (COVID-19). Retrieved from https://doi.org/10.1101/2020.03.01.20029611/ Accessed 12 May 2020. 